\title{
SOBRE LA ESCRITURA DEL ÁRABE COLOQUIAL UNAS NOTAS ACERCA DE LAS VOCALES BREVES
}

\author{
Carmen RUIZ BRAVO-VILLASANTE \\ Universidad Autónoma de Madrid
}

\begin{abstract}
Para Maria Jesús Rubiera. Su mirada atenta y viva a lo escrito y aludido nos demuestra siempre la posibilidad del diálogo. Estos trazos son, además de un homenaje a las enseñanzas de árabe dialectal en que nos inició junto a D. Elias Terés, cuando era muy joven profesora en la Universidad de Madrid, una humilde manifestación de mi gran admiración y agradecimiento actuales y permanentes hacia su labor cientifica y su persona.
\end{abstract}

La escritura árabe es lo suficientemente dúctil como para reflejar tanto el árabe en el registro o modalidad fusha como en el de la 'ámmiyya, y los intermedios entre ambos. De hecho, cuando los árabes escriben normalmente el árabe coloquial lo hacen en el mismo sistema de escritura que el árabe más "literario", seleccionando los rasgos del coloquial que consideran deben consignarse por escrito, y prescindiendo de los demás a efectos de escritura.

Los textos que hemos consultado ${ }^{1}$ nos indican cuáles son los rasgos coloquiales que pasan a la escritura:

\section{La escritura de las vocales}

Habitualmente la escritura del árabe coloquial omite los signos de vocal breve, que se reconocen, como es normal en la grafonomfa árabe, por la estructura general escrita de la palabra, o sea, por la estructura consonántica y por contraposición y complementareidad con las vocales largas, de las que sí se escribe el signo de prolongación.

${ }^{1}$ Véase Nota final. 
Esta característica de la escritura árabe, a saber, la posibilidad y costumbre de no consignar por escrito la vocal breve, conviene sobre todo al registro coloquial, ya que en él la mayor parte de las vocales breves se realizan como vocales de timbre bastante desdibujado, como vocales "de paso" desde la articulación de una consonante a la siguiente. Eso que he llamado "desdibujamiento" está descrito con perspicacia por el $P$. Lerchundi como "un sonido vago y peculiar que no se puede representar por nuestras vocales"2. La variabilidad de dichos fonemas depende de la naturaleza de las consonantes de su entorno, de las características del dialecto en que se expresa el hablante, y del registro lingüŕstico concreto que éste emplee en cada momento ${ }^{3}$ : cuanto más presente se tenga la referencia "literaria" o faṣiha, más se podrá percibir un cierto "aroma" (tašmím, como decían los fonetistas árabes clásicos) del timbre del esquema originario.

\section{Vocal breve y hamza}

Pero, a veces, el que escribe el árabe coloquial tiene que señalar el timbre de la vocal, o puede, o quiere hacerlo; y lo hace por ciertos procedimientos que le permite el sistema de escritura. Al pensar en estas cuestiones nos resulta muy evidente la función que tiene la hamza en cualquier registro, además de como consonante, como auténtica indicadora gráfica del timbre de la vocal breve, que se especifica por escribirse sobre $w \bar{a} w$, o sobre $y \tilde{a}^{\prime}$.

Es muy frecuente encontrar escrita la hamza en textos de árabe coloquial, tanto al menos como en árabe fuș̣a. En ellos puede servirnos

${ }^{2}$ Lerchundi, El M. R. P. Fr. José: Rudimentos de árabe vulgar que se habla en el Imperio de Marruecos... Tánger: Tipografía hispano-arábiga de la Misión Católica, 1925, p.12. Al transcribir el árabe coloquial con nuestras vocales habituales en un primer momento facilitamos a los hispano-hablantes el acercamiento al árabe coloquial. Sin embargo, luego pudiera ser que eso les apartase de entender la realización de dichas vocales.

3 Véase una deliciosa descripción acerca de la escala de registros de un académico egipcio en las páginas XIII y XIV del prólogo que Emilio García Gómez pone a la obra de Federico Corriente: A Grammatical Sketch of the Spanish Arabic Dialect Bundle. Madrid: Instituto Hispano-Árabe de Cultura, Dirección General de Relaciones Culturales, 1977. 
como clave de referencia la forma en que se escriben los pronombres personales:

\section{La hamza del pronombre personal}

Algunas veces, es precisamente la situación de la hamza la que permite saber que nos encontramos en dialectal, pues se puede optar por escribir la hamza encima o debajo del alif, según se perciba la vocal como una fatha o más bien como una kasra. Por ejemplo, en el caso del árabe coloquial egipcio, en aquellos textos que escriben la hamza del alif, se observa que es muy habitual escribir el pronombre personal tú como con kasra en lugar de con fatha, puesto que la hamza se escribe bajo el alif:

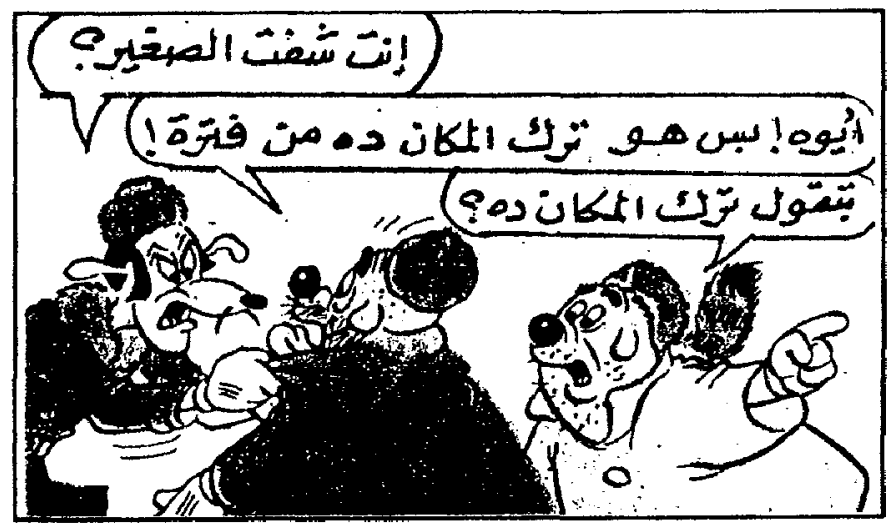

¿Has visto al pequeño?

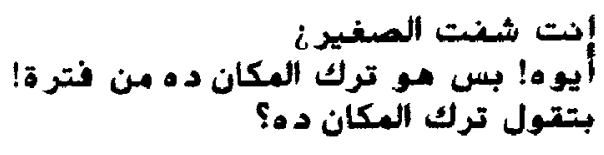

¿Sí! ¡Pero se ha marchado de ahí hace un rato!

¿Que se ha marchado de ahi?

(Tebeo Miki, p.4)

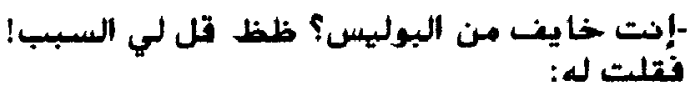

-¿Tienes miedo a la policía? ¡Dime por qué!

-بكره القول لك. خلينا الساعة للنن!

Le contesté: 
-Mañana te lo digo. ¡Vamos ahora con el arte!

(T. al-Hakīm, Dikrayāt..., p. 34)
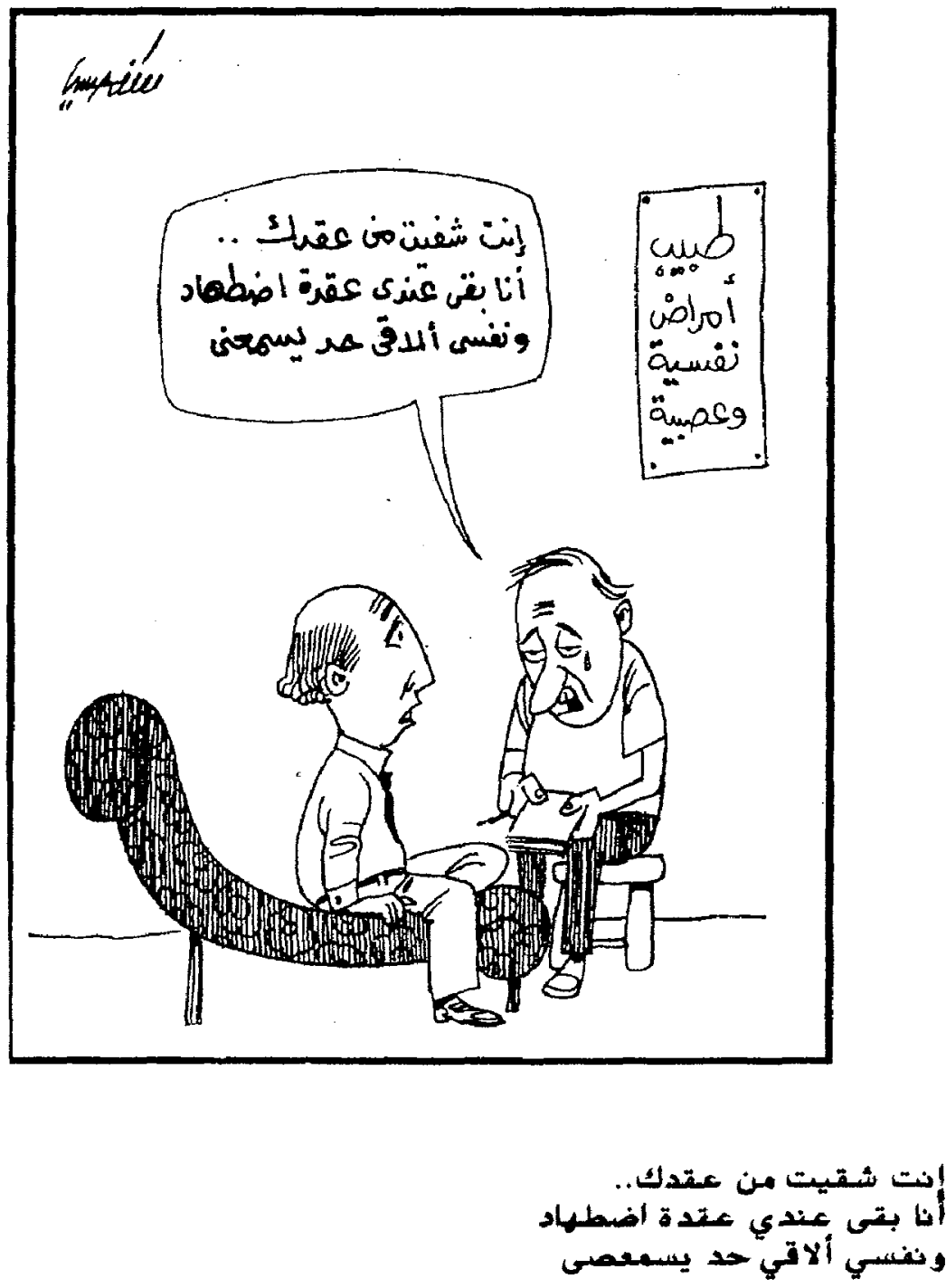

Usted ya está curado de complejos.

Pero a mí me queda un complejo de represión y tengo que encontrar a alguien que me oiga. 


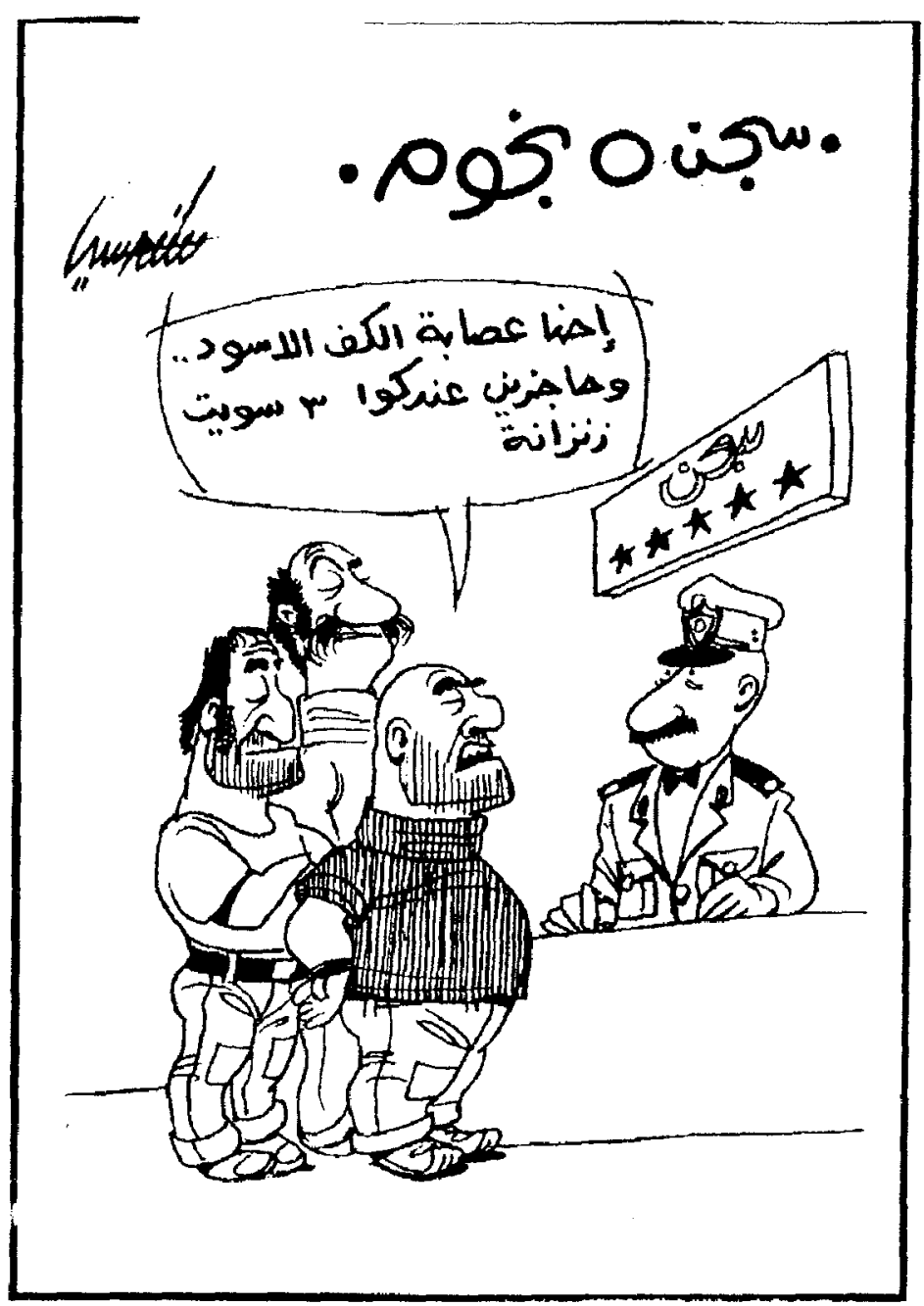

Somos la banda de la mano negra...

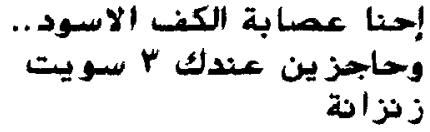

Tenemos reservadas 3 cárceles suit. 
En otros textos que he consultado, también en coloquial egipcio, o en coloquial iraqui, o marroqui, he encontrado variantes: unas veces sin hamza (y me refiero a textos en los que también se encuentra dicho signo), y otras como con fatha (entiendo que escribir la hamza alif, en este caso, es señal de que hay fatha), y otras con kasra. A continuación aduzco los ejemplos correspondientes:

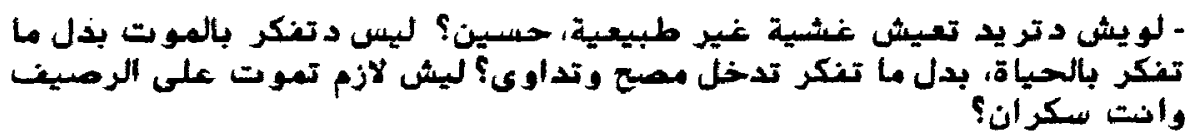

- ¿Por qué quieres vivir una vida que no es normal, Husayn? ¿Por qué piensas en la muerte en vez de en la vida, en entrar en un hospital y curarte? ¿Por qué tienes que morir sobre la acera, borracho?

(En p. 106, Tekerin) sin hamza.

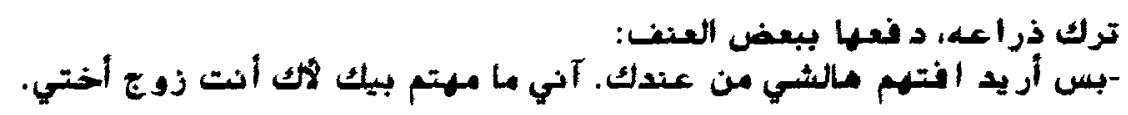

Se soltó del brazo, la empujó algo violento:

- Sólo quiero que entiendas una cosa. Yo no me preocupo por ti porque seas el marido de mi hermana.

(Idem, con hamza. Nótese que el pronombre no se afija detrás de la partícula)

Un ejemplo muy interesante es el que se da en un poema de Riyād al-Nu'mānī (p. 51) en el que aparece el mismo pronombre, en dos líneas consecutivas, con las dos grafias posibles a las que nos hemos referido: con kasra, la primera vez, y con fatha, la segunda. Parece que se percibe ahí un cambio de registro, que quizá tenga que ver con el propio poema, que se mueve entre dos registros, uno más humano, y otro más sacro. 
SOBRE LA ESCRITURA DEL ÁRABE COLOQUIAL...

643

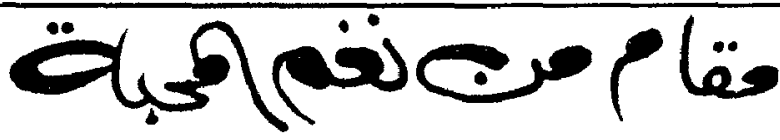
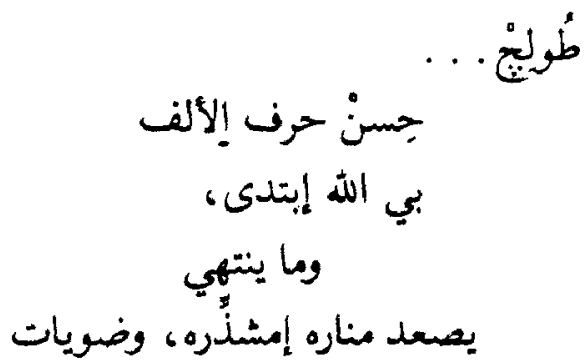

' وجهيج،

كربلا، ورايات

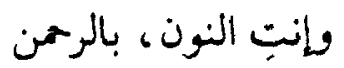

وأنت

الميم

بيه إنختمت الآيات

من حروب إطويله يطلع

eres la nūn, en al-Raḥmān

tú eres

la mìm

con eso quedan selladas las aleyas

En los poemas de Michel Țrād, escritos en dialecto libanés, el pronombre aparece también con hamza debajo del alif. El pronombre 
mantiene la hamza, cosa que en otro tipo de escritura de textos coloquiales no sucede:

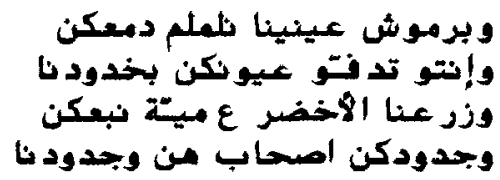

Con las pestañas de nuestros ojos recogemos vuestras lágrimas

$Y$ vosotros calentáis los ojos en nuestras mejillas

Plantamos el verde con el agua de vuestro manantial

Vuestros antepasados son amigos de los nuestros

(Cuarta y penúltima estrofa del poema Pirän, p.67)

En algunos textos (dialectal egipcio de Yūsuf Idrīs, poemas en dialectal marroquí de Ahmad Lamsayyah, p. 43) observamos que se evita frecuentemente escribir éste y otros pronombres con hamza. En el texto de Yüsuf Idrīs, y en el poema en dialectal marroquí la escritura de hamza se reserva para la hamza que es de la raiz. Quizá se considera que no es adecuado conceder un reconocimiento fonético/gráfico a la propia hamza, y por tanto a su vocal, que no es propiamente ni fatha ni kasra, toda vez que en el registro coloquial dialectal que se emplea tiende a una realización desdibujada, próxima a la $/ \partial /$, en los dialectos orientales, y casi como cero en el coloquial marroqur.

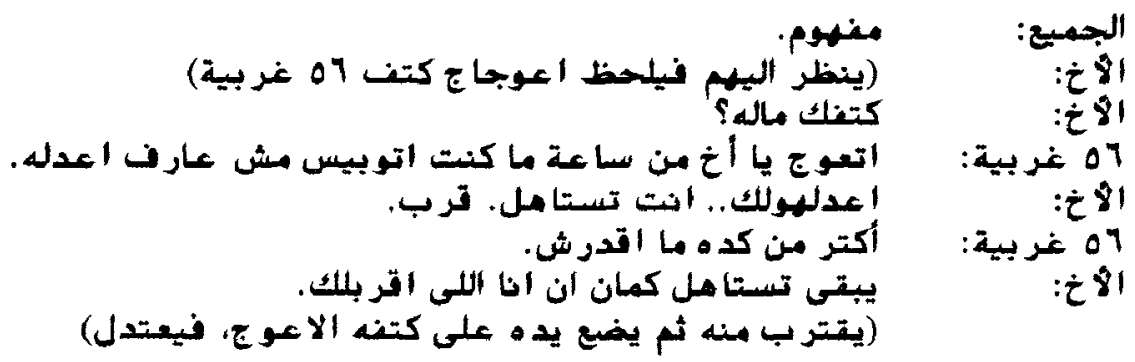

E1 hermano: Yo te lo arreglo...tú, preparado. Acércate.

56 Oeste: Más no puedo.

El hermano: Sigue preparado, a ver si me acerco yo. 
Escribe, engalanaos, Farīd tú y Būhālī.

Nada se os reprocha

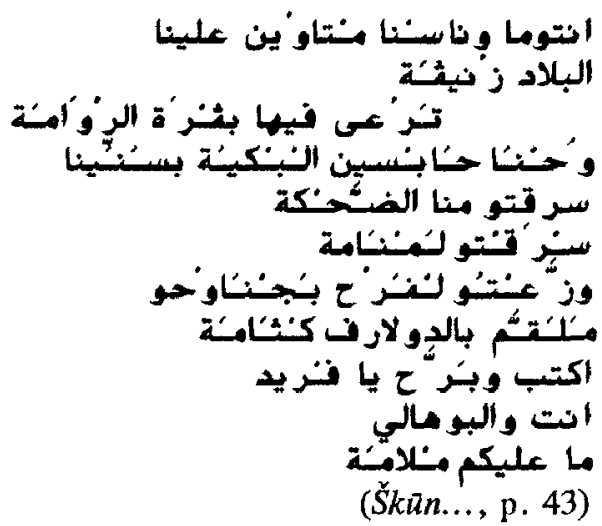

Este último tratamiento dan todos los textos, escritos en coloquial, al articulo, que se escribe sin hamza. Escribirlo con hamza se consideraría un rasgo hiperculto. En cuanto a las demás hamza-s, se escriben o no según las tendencias que hemos señalado: unos textos no las escriben nunca si no son de la raíz, considerando que su pronunciación no es pertinente; los otros, por el contrario, sí parece que consideran su pronunciación/escritura pertinentes, y las escriben según se pronuncien o no en el contexto fonético concreto de cada frase.

La tendencia a suprimir gráficamente incluso el alif se da en algunos textos. Suponemos que ello puede dificultar la comunicación entre el registro 'ámmiyya y el registro fushà, donde se suele seguir escribiendo.

\section{Vocal breve y sílaba final}

La lengua árabe evita terminar las palabras en vocal breve, ya que la vocal breve final está reservada para unir las palabras entre sí. En el registro de la fushà, la vocal de unión toma un timbre bastante definido (fatha, kasra, damma) según los casos; en el registro 'ámmiyya, por el contrario, la vocal de unión es de timbre tan desdibujado como la vocal pretónica. Sin embargo, parece que se suele diferenciar de ésta por ser algo más abierta y no ser tan breve.

La vocal de unión no se escribe en el registro coloquial.

Pero ¿se pronuncian las palabras unidas en el árabe coloquial? Ahí si que nos encontramos con variantes, tanto dialectales como personales, o también situacionales. 
-La escritura del alif, y la de la tá marbüta son dos excelentes indicadores para saber cọmo hay que pronunciar el texto, si hay que ligar las palabras, o si se pronuncian más bien separadas. Y ello es importante para conocer la medida, en los textos poéticos, como los que aducimos. O para transmitir la forma de hablar, más o menos entrecortada o fluida, pausada o acelerada, narrativa o dialogada, de los personajes.

En los textos en que se emplea el alif con hamza, la escritura del alif sin ella ya es indicio gráfico de pronunciación ligada, y señal de que hay que introducir vocal de unión ${ }^{4}$. Es un procedimiento general empleado por la lengua árabe.

-La tã 'marbüta de los femeninos es ya un indicador de que la vocal breve anterior se pronuncia con nitidez. AsI, se suele escuchar en árabe coloquial la fatha como /a/, con algunos alófonos muy próximos. La tă marbüta se escribe/pronuncia en dialectal cuando está ligada a la palabra siguiente (en los registros medios, en que se utiliza la idăfa o complemento del nombre; o simplemente cuando al femenino sigue otra palabra sin que medie ninguna pausa). En cambio, cuando se hace una pausa, especialmente la pausa de final de frase, podemos encontrarnos con que la $t a^{\prime}$ marbüta ya no se escriba como tal, y de algún modo se transforme. Esto no se suele dar en textos narrativos. Cuando lo hemos encontrado, ha sido, concretamente, en algún otro tipo de texto oriental.

La $t \bar{a}^{\prime}$ marbüta puede aparecer sustituida por una $h \bar{a}^{\prime}$, ante pausa.

Así, el siguiente chiste del diario al-Šarq al-Awsat, de la serie "Don Hipócrita":

${ }^{4}$ Por cierto, cuando se transcriben los textos del registro fuṣ̣à en letras latinas hay mucha costumbre de utilizar un solo signo de vocal breve, la $\langle a\rangle$, como signo para la vocal de unión, omitiendo las variaciones de timbre de los casos. Realmente esa forma de transcribir refleja más bien un registro si no coloquial, sí cercano al coloquial. Es decir, una lengua árabe faștha, más que fușhìa. 

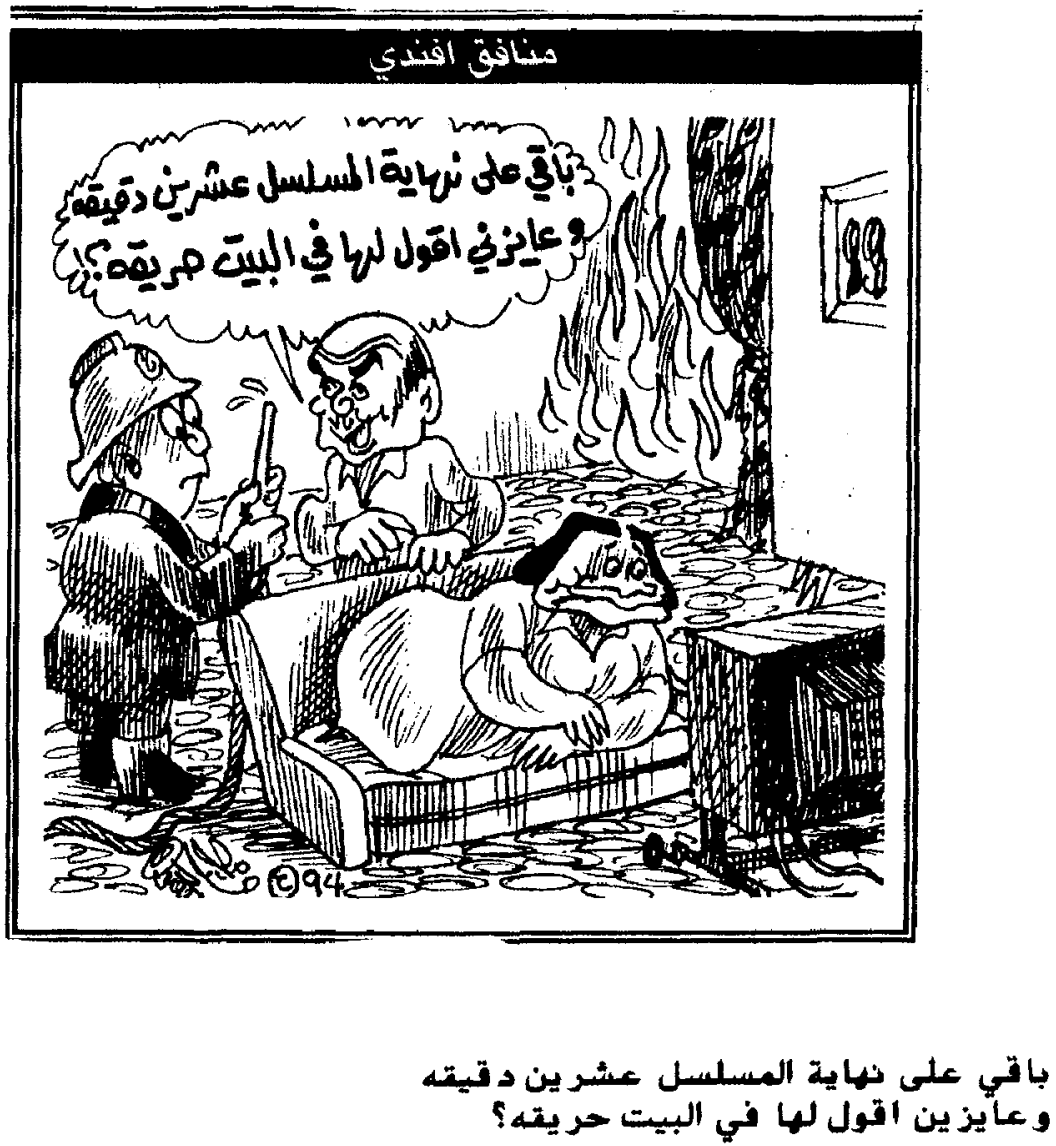

Quedan veinte minutos para que termine el episodio ¿y quiere que le diga que hay un incendio en la casa?

Es posible que esta práctica gráfica sirva para reflejar algunas características dialectales, tales como pronunciar la vocal breve fatha de la sílaba final no sólo claramente como /a/, sino además con una leve $/ \mathrm{h} /$, similar a la desinencia andaluza $/ \mathrm{a}_{\mathrm{h}} /$ con que se pronuncia $<\operatorname{las}>^{5}$.

5 Véase la transcripción del "Cuento de la hormiguita", por Manuel Alvar, citado, con comentario, por Manuel Ariza: Comentario de textos dialectales. Madrid: Arco/Libros, S.L. 1994, pp. 68-71. La costumbre de no diferenciar, en 
Un caso peculiar es el que se da en la escritura de coloquial libanés, en el texto de Michel Ṭrād, donde se refleja en algunas palabras la pronunciación šāmī de la fatha final del femenino como /a/ (en determinados contextos consonánticos). Para representar este fenómeno se opta por colocar como desinencia una $y a^{\prime}$, entendiéndose que esta escritura representa mejor el fonema resultante que otra desinencia.

Una niña, y en su mano una muñeca. Su vestido, mariposas; su zapato, una rosa.

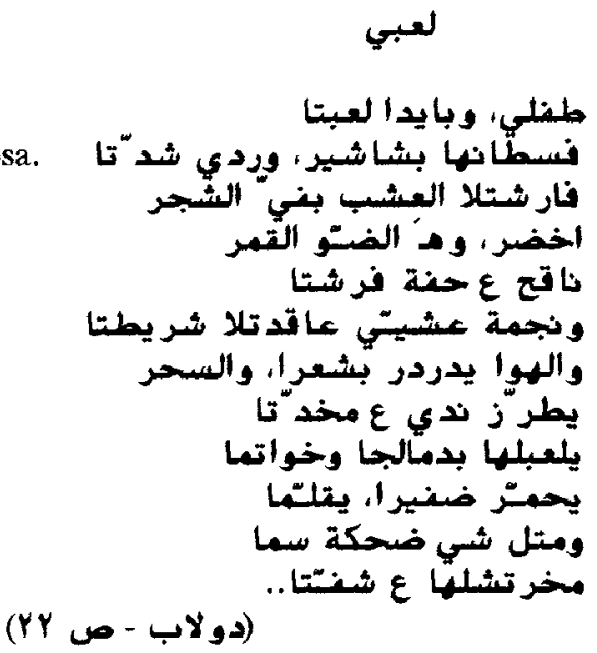

En ambos casos, con la $h \tilde{a}^{\prime}$, o con la $y \bar{a}^{\prime}$, se alude a que la vocal puede tener, por posición, más duración que la vocal breve normal. De hecho, en general la vocal breve de una silaba en posición final, aunque no sea tónica, se realiza como más larga que las otras vocales breves. $\mathrm{Si}$ además lleva una determinada entonación propia de su situación en "juntura" sintáctica, puede quedar alargada o/y acentuada en cuanto a entonación.

En este sentido, es interesante observar que existe la costumbre de escribir la $y \bar{a}^{\prime}$ sin puntos diacríticos para señalar la existencia de una vocal kasra breve en posición final. Desde luego que este tipo de

la transcripción con letras latinas, entre las palabras escritas con/sin tä ${ }^{\prime}$ marbüta nos impide saber cómo son los textos originales (si carecemos de ellos) en grafía árabe. Y esto, para el árabe coloquial, y aun para la lengua árabe fuṣ̆hà, puede marcar diferencias de lectura. 
recurso se suele emplear cuando tipográficamente está excluido totalmente el uso de signos para vocales breves. A veces nos parece que también obedece a una voluntad estilística de subrayar lo dialectal, o incluso lo vulgar.

Véase, en la siguiente página, este chiste de al-Hayă':

El pronombre femenino termina asi para que se pronuncie claramente la kasra, pues si no llevara esta letra se leería como el masculino, con una fatha; a su vez, el nombre Fifi, en el chiste, aparece con dos $y \bar{a}^{\prime}-\mathrm{s}$, la primera es de alargamiento y lleva el acento, mientras que la segunda alude a una realización breve, y no lleva puntos diacríticos, por lo que en árabe se pronuncia /Ftfil, como en inglés (y no como en francés), acentuando la primera de las dos sílabas.

El pronombre afijo (tercera persona, masculino, singular)

Los textos nos presentan dos formas de escribir este pronombre afijo: una, manteniendo la $h a^{\prime}$ (la desinencia se leeria $/ \mathrm{u}_{\mathrm{h}} /$, de manera similar a como se leía la desinencia de femenino $/ a_{h} /$ ); la otra, suprimiéndose la $h \widetilde{a}^{\prime}$, la sustituye por una wâw.

(Es interesante observar que en bastantes textos la desinencia $/ \overline{\mathrm{u}} / \mathrm{de}$ la persona "ellos" del verbo aparece además con alif "ocioso", igual que en la escritura del registro fusha. Con ello se contribuye, sin duda, a distinguir rápidamente entre desinencia verbal y pronombre afijo).

Valgan estas observaciones como unas primeras notas acerca de la escritura del dialectal. Como se ve, la grafía árabe puede expresar la diversidad de registro ( $\mathrm{y}$ dialecto) $\mathrm{y}$ tiene unos procedimientos para ello. Por eso tendemos a estudiarlos y utilizarlos corrientemente, siguiendo una práctica que tiene siglos de desarrollo. Quizá, de no ser así, aumentarían las tendencias diglósicas, puesto que "cambiando la grafía se pueden provocar escisiones entre los hablantes de una misma lengua o de lenguas muy próximas"6.

${ }^{6}$ Giorgio Raimondo Cardona: Antropología de la escritura, Madrid: Editorial Gedisa, 1994, p.115. 


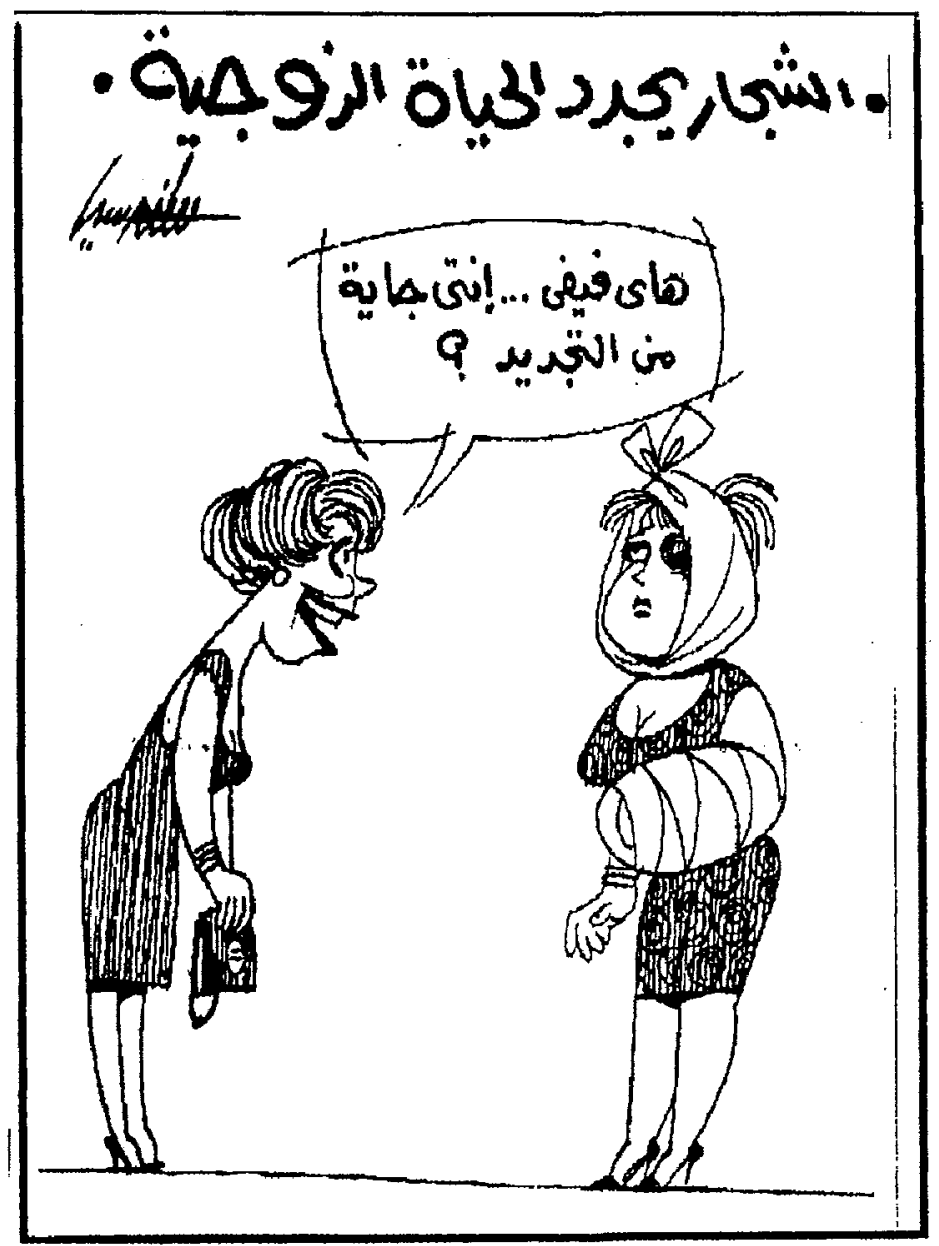

Reñir renueva la vida conyugal Hey, Fifí... ¿Vienes de renovación? 
NOTA FINAL: Se han reproducido algunos textos en su contexto gráfico inmediato, porque puede ser de interés para entender el sentido del texto:

Los textos citados son:

- AL-HAKİM, Yūsuf: Min dikrayāt al-fann wal-qadà'. El Cairo: Dār al-Ma'ārif, col. Iqra', n' 126 , junio 1953, p. 34.

- HUSAYN, Mustafa: Varios chistes aparecidos en el diario al-Haya ${ }^{t}$ (Londres), 1994. Este material es parte del que me viene proporcionando el Prof. Pedro Martínez Montávez, quien llamó la atención sobre el valor del humor gráfico árabe en la exposición que preparó para el Curso de verano de la Universidad Complutense en Aguadulce (Almería), en 1992.

- IDRĪS, Yūsuf: al-Mujatțațn. El Cairo: Maktabat Miṣr, 1977, p.22.

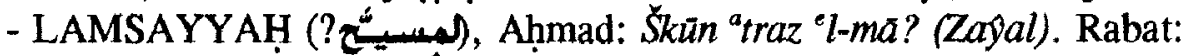
Mațba'at al-Ma'ārif al-Ŷadída, 1994, p.43. Este libro me lo ha proporcionado y dado a conocer Gonzalo Fernández Parrilla.

- LYONS, M.C.; MAALOUF, E.I.: The Poetic Vocabulary of Michel Trad. A Study in Lebanese Colloquial Poetry. Beirut: Librairie du Liban, 1968, p.67-68. (Portada secundaria, y gran parte del texto, en árabe).

- MİKI (Maŷalla usbü'iyya taṣdur min Mu’assasat Dār al-Hilāl). $\mathrm{N}^{\circ} 486$, agosto $1970, \mathrm{p} .4$.

- AL-NU'MĀNII, Riyăḍ: Imäm al-ward.(Ši 'r ša 'bī 'irāqū). Damasco: alAhālī, 1990, p. 51. Este libro me lo ha proporcionado y dado a conocer el poeta iraquí, residente en nuestro país, Kamal Sebti.

- AL-ŠARQ AL-AWSAT (Londres...), 1994. También proporcionado por el Prof. Martínez Montávez.

Mi propósito es seguir desarrollando esta indagación en otros trabajos. Como habrá podido comprobar el lector, existen otros fenómenos relativos a la vocal breve, algunos de los cuales aparecen incluso en los textos aquí reproducidos. 